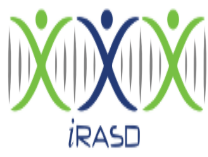

iRASD Journal of Management

Volume 3, Number 3, 2021, Pages 258 - 267

Journal Homepage:

https://journals.internationalrasd.org/index.php/jom

\title{
Technology-Performance Nexus during Covid-19: A Case of Commercial Banks from Selected South Asian Economies
}

Syed Muhammad Abdul Rehman Shah ${ }^{1}$, Kashif Razaㄹ, Asif Raza ${ }^{3}$, Ismat Nasim ${ }^{4}$

${ }^{1}$ Lecturer of Islamic Banking and Finance, Department of Basic Sciences, University of Engineering and Technology Taxila, Pakistan, Email: a.rehman@uettaxila.edu.pk

${ }^{2}$ Lecturer, Department of Economics, The Islamia University of Bahawalpur, Bahawalnagar Campus, Pakistan, Email: kashif.raza@iub.edu.pk

${ }^{3}$ Assistant Treasurer, The Islamia University of Bahawalpur, Pakistan, Email: asifraza@iub.edu.pk

${ }^{4}$ Lecturer, Department of Economics, Government Sadiq College Women University, Bahawalpur, Pakistan, Email: ismat.nasim@gscwu.edu.pk

\section{ARTICLE INFO ABSTRACT}

Article History:

Received:

Revised:

Accepted:

November 04, 2021

December 28, 2021

December 28, 2021

Available Online: December 29, 2021

\section{Keywords:}

Technological change

Employee's performance

Commercial Banks training

Supervisor support

Incentives

Pandemic covid

\begin{abstract}
Technology acceptance affects performance of employees in emerging organizations. This study explores the relationship between technological transformation and performance of the employees of commercial banks from selected Asian economies during Covid-19 pandemic. We also analyze the effect of moderators; training, supervisor support and incentives on this relationship. We have tested the hypotheses by means of the survey of 400 employees of commercial banks from selected South Asian economies of Bangladesh, India, Sri Lanka, Maldives, and Pakistan. The Pearson correlation and multiple linear regression techniques are utilized to investigate the research problem. The identity theory and social learning theory reflects that the individuals get satisfied while relating themselves with the objectives of organization and the goals of nation. Further, they participate in the organizational and national development through technical innovation process if provided with supervisory support, training and incentives. This study recommends to executive management to adopt modern technology for sake of the higher objectives of firms' performance in a Post- Covid depressed economies.
\end{abstract}

(c) 2021 The Authors, Published by iRASD. This is an Open Access article under the Creative Common Attribution Non-Commercial 4.0

Corresponding Author's Email: a.rehman@uettaxila.edu.pk

\section{Introduction}

Modern technologies are essential part of any organization in modern era of competition. Organizations attain new skills and also improve the skill level of their employees because new technology is significantly different from the ancient technologies. Park et al. (2020) have documented that the use of an integrated information technology system facilitated firms to allocate the resources efficiently in amidst pandemic of covid-19. During prevailing epidemic, organizations are pushed to accept latest technologies to keep themselves profitable. Training is often used to congregate the challenge in the organization because training is cheap when skill requirements are firm-specific. Users 'attitude towards adapting new technologies is altered through accurate training and supervisors' support. Employees' training programs are arranged and incentives are given to develop useful competencies for future organizational development and change (Ismail et al., 2010). In Kenya from 2014 to 2018, Muthaura et al. (2021) noted to a deep influence of Fintech, for instance, the number of digital loans processed, digital accounts acquired, digital transactions, ATMs, and bank agents on financial performance of commercial banks. 
Interestingly, Zuo et al. (2021) have documented that performance gains in the commercial banks have also been associated to accept modern technologies for product development. So, it is vital for the organizations to adopt the modern technologies for sake of higher productivity in amidst pandemic of covid-19. Therefore, it is interesting to explore the nexus of technology-performance in handful way.

The arrival of COVID-19 in consecutive intervals have created worse situation in human history across the globe. People are reluctant to leave their homes and want to work from home as employee. Due to the fear of catching the virus, they prefer to keep themselves in solitary confinement. In almost all countries of the world, governments have lock downed to quarantine the people, industries are partially operating, markets are partially opened, and food items are becoming more expensive. Thus, most of industries, corporations, companies, and institutions are evicting their people due to economic and financial crises caused by the COVID-19. Consequently, unemployment in corporations is on the rise. There have been massive and extraordinary rise in workers submitting unemployment insurance claims in several different countries of the world (GoldsmithPinkham and Sojourner, 2020). Employees on job are suffering from psychological stress due to the fear of being unemployed in the context of the COVID-19 pandemic. According to an estimate, almost 25 million people across the globe are at risk of losing their jobs worldwide as a result of COVID-19. The situation is paralyzing governments, corporations, and citizens at all. Kawohl and Nordt (2020) have documented that this led to an increase in suicide ideation and ill behaviors among populations, failure of governing authorities. Profitable firms are pushed to survival in amidst pandemic of covid-19. Commercial banks are not exception while facing these economic problems.

In modern era of information and technology, organizations have developed at an exceptional rate and continued to experience the changes determined by adoption of contemporary technology. Organizational and national conditional performance and development are determined by the state and types of technologies you adopt in an organization. Technology also influences living conditions of individuals, groups, organizations, nations, and the relationships among them (Prasad, Vaidya, \& Mangipudi, 2020). To accept this impact of technological change acquires to investment in highly developed technologies and to used highly capable labor in organization. This study explains "skill-based technological change" needs to hire highly skilled workers than lessskilled ones. This drift is interesting, given that research fails to link technology implementation to enhance organizational performance. Therefore, this research aims to study the relationship between technology change and employee outcomes. Multifactor productivity (MFP) growth reflects the idea of technology alteration. The MFP residual was in early estimates of sources of development incredibly high. One probable resource of MFP growth is various complementarities between inputs. Basically, this study is conducted to investigate the impact of technological changes in the organizations on the employee performance and the influence of supervisor support, training and incentives on this relationship in commercial banks from selected Asian economies of Bangladesh, India, Sri Lanka, Maldives, and Pakistan. These countries are selected because of common characteristics of banking sectors of them. Their economies are partially dependent on banks to fuel their economic activities. There are two basic objectives of study. First, we intend to analyze and explain the relationship between technological transformation and employees' performance in commercial banks during pandemic of covid-19. Second, our objective is to analyze the influence of supervisor support, training, and incentives on the relationship between technological change and employee performance of commercial banks in abovementioned south Asian economies. 
Introducing the subject matter of study, we have reviewed the literature in second section. The third section explores the data and research design. In fourth section, findings of study are discussed in detail. In last section, we have concluded the subject, recommended the policies, and mentioned some limitations of study.

\section{Literature Review}

In competitive firms, managers, supervisors and employees play a vital role to promote technology innovation for organizational competitiveness. Many organizations realized to consistently promote the significance of technological innovation to firms' performance. Dynamic technological transformation still needs to apply the skills in practical ways for improved technological innovations. Corporations provide gears for enhancing performance when change in technology occurs. Despite uncertainties found in economic markets after Covid-19, Walrave et al., (2021) have found that firms are adopting disruptive technologies and finding new online business models, which result in betterment of their performance. Phan et al., (2021) have measured the impact of FinTech on banking sector performance through different alternate performance measures, like ratio of net interest income to total assets (NIM), ratio of net income to total assets (ROA), ratio of net income to total equity (ROE), and yield on earning assets (YEA) for a panel of 41 banks over the period from 1997 to 2017. During analysis, they have augmented the traditional banking performance model with FinTech measure and found that FinTech growth hinders banks' performance.

The outbreak of corona virus initiated as pneumonia of unknown cause in December 2019 in Wuhan, China, which has been now spreading rapidly out of Wuhan to other countries. On January 30, 2020, the World Health Organization (WHO) declared coronavirus outbreak as the sixth public health emergency of international concern (PHEIC), and on March 11, 2020, the WHO announced coronavirus as pandemic. The global economic crisis triggered by COVID-19 is totally different as compared to that of in past ages. In this era of informational technology, globalization, and economic and financial integration, COVID-19 has created a panic at much higher scale. It is natural that the fear of death overwhelms the mankind and thus, various potential alternative precautionary measures have been taken. Although these measures temporarily save them from death, they create other big and serious problems. To prevent the COVID-19, the quarantine and lockdown have eventually increased social unrest, anxiety, insecurity, and unemployment in several economies of the world. This situation led organizations to adopt modern technologies and transform their typical local market to global digital markets.

Technological changes and innovations are initial points of the ideas to make a firm's business profitable and these are initiated and managed by employees of corporations. The Identity theory is provided to assess individual relations to organizational objectives and national goals. Technology change took place by inspiration and inclination of comprehend human resource. Human resource performance is thoroughly linked to technological transformation and technological innovation. Technological transformation could be successfully managed through human resource combined approach. Individuals can innovate and accomplish great technological breach, but the complexities of current technology require effective combination of different innovations based on different aspects of technology(Vahdat, 2021). The strategies of change beliefs, attitudes, values and structure of an organization are provided by this theory so that they can adapt new technologies, challenges, and changes in the best way of professional practices. It can plan the intervention in organization process for increase organization growth and health. Substitution strategies were successful, which were coming up against technological tiredness (Ervinta1, Prihanto, \& Sudiyono, 2021). 
In any organization, the status of technology regular change in organizations has to observe, supervise and cope with the technology need. The insurance of employees that are trained and involved in the management of technological transformation for organizational survival is necessary for the manufacturing industry. But the most of firms get outcome of low profitability and bad performance because they tend to undermine the input of employee in managing technological change. The application of physical forces from different types of technology has impact on the Productions of goods and services. Technology provided the required skills by which goods and services were produced (Dauda, 2010).

Organizations should emphasize on the development and protection of individuals and group welfare for managing technology modernism.HR explosion of knowledge that is taking place today. Present condition dynamic which is dangerous for an organization and nation to rely on the present achievement, hence, so that needs to modernize the technology especially in bitter days of COVID-19. Organizations and nations do not wait for technology limit in modern era of technology; hence, HR requires constant development on the following aspects to keep a corporation alive.

\subsection{Training}

It is vital to invest in employee development for improving the skills and abilities of employees and organizations. Furthermore, social exchange theory shows that employees behave in positive ways when the organizations invest to them. Training is a methodical development of the knowledge, skills and attitudes required by employees to achieve sufficiently on a specified assignment or trade. It is need of day to prepare employees of organization to counter bad conditions of COVID-19. Sapta et al., (2021) have stated that overall usefulness and profitability of an organization relies on the staff training. They, therefore, provide a complete set of methodology which covers the main elements of training. Further, Martínez-Caro et al., (2020) have noted that the developing competences such as technical, human, conceptual, and managerial for the furtherance of individuals and organizations' growth is gained through effective training (Martínez-Caro, Cegarra-Navarro, \& Alfonso-Ruiz, 2020).

\subsection{Supervisor support}

Supervisor support is defined as the extent to which firm's leaders value their employees' contributions and care about their well-being. Supervisors have responsibility for directing and evaluating subordinates' performance in an organization. Infect, employees note their supervisor's favorable or unfavorable orientation toward them as indicative of the organization's support (Wolor, Solikhah, Fidhyallah, \& Lestari, 2020). Additionally, employees understand that supervisors' evaluations of subordinates are often conveyed to upper management and influence upper management's views. Furthermore, (Angioha, Enukoha, Agba, \& Ikhizamah, 2020) noted that supervisor's support makes employees willing to put extra efforts for betterment of corporations, which is earned through supporting environment. Likewise, Trushkina, et al., (2020) documented that a high supervisor support is explained with a leader who makes employees feel heard, valued, and cared about.

\subsection{Incentives}

Although employees may be capable and experienced to perform their routine tasks at the workplace, they also need to be motivated to apply their usual and flexible effort for achieving extraordinary levels of performance (Trushkina, Abazov, Rynkevych, \& 
Bakhautdinova, 2020). Motivation, thus, reflects an employee's willingness to go extra miles for the organization (Jiang et al., 2012), and is obvious in the strength, way and duration of employees' hard work toward work accomplishments for attaining high performance (Jiang et al., 2012). Encouraging employees to employ such energies typically involves providing rewards and incentives for employees (Bartol \& Srivastava, 2002). Furthermore, (Angioha et al., 2020) and Li, et al., (2020) established much prior the impact intrinsic and extrinsic rewards as incentives to get desired behaviors from workers. Interestingly, incentives influence the reciprocity and as a result developauspicious desired attitudes and behaviors of employees (Minbaeva, 2013). Recompensing new abilities and knowledge establishment also inspires employees to experiment with novel ideas and new knowledge creation (Molino, Cortese, \& Ghislieri, 2020).

In prevailing circumstances of COVID-19, governments are taking short-term measures in emergency and people are also trying to somehow get rid of economic hardship. Corporation's performance is not an exception in amidst pandemic of covid-19 and trying to find out the ways to keep their business profitable. In principle, the concept of Islamic banks is relevant to the growth and development of economies. Islamic banks are good opportunity for governments and corporations to show its true contribution and broad capabilities to the Post Covid-19 world. Interestingly, it is obvious that emerging Islamic banks are more concerned about to adopt modern technology for their enhancement in market. Further, supervisor support, training, and incentives are relevant to Islamic socioeconomic norms as the objectives of Shari'ah. Islamic banks have all those characteristics and capabilities because of which it can achieve some of higher Maqasid alShariah (the objectives of Shari'ah) which covers almost socio-economic objectives of SDGs (Shah et al., 2020). Therefore, Islamic banks as part of commercial banks have potential to play a vital role in achieving the relationship between technological change and employee performance in to reduce the adverse socioeconomic effects of COVID-19.

While reviewing literature, we find potential gap to investigate the relationship between technological change and employee performance for commercial banks. Therefore, this study intends to analyze the relationship between technological transformation and employee performance in commercial banks during pandemic of covid-19. Further, we analyze the influence of supervisor support, training, and incentives on the relationship between technological change and employee performance in commercial banks.

\section{Hypothesis}

Based on the above literature and the supporting theories we propose that

$\boldsymbol{H}_{1}$ : Technological changes positively affect the employee's performance of commercial banks

$\boldsymbol{H}_{2}$ : Employee's training moderates the effect of technological transformation on employee performance of commercial banks

$\boldsymbol{H}_{\mathbf{3}}$ : Supervisor's support moderates the effect of technological transformation on employee performance of commercial banks

$\boldsymbol{H}_{4}$ : Incentives moderate the effect of technological change on employee performance of commercial banks 


\section{Research Methodology}

The research model is designed to observe the impact of technological transformation on employee performance of the commercial banks of selected south Asian economies in the Amidst Pandemic Era. Further, the impact of technological transformation (TT) on employee performance (EP) is moderated by supervisor support (SS), incentives (IN) Training ( $T$ ) to meet the objectives of study. The following model facilitates us to meet the research problem in specific framework as adopted by Jiang et al., (2012).

\section{Research Model}

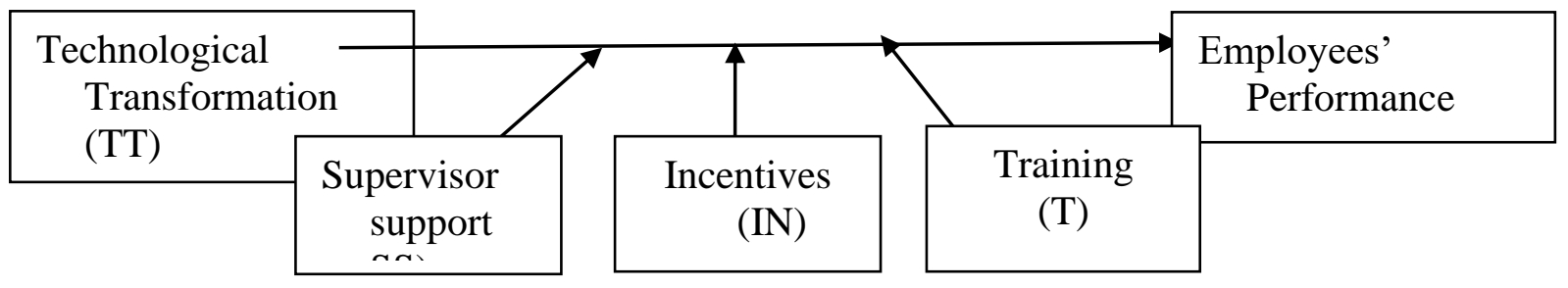

\subsection{Sample and Procedure}

The sample for the study was drawn by conducting a survey of the employees of commercial banks from selected South Asian economies of Bangladesh, India, Sri Lanka, Maldives, and Pakistan. A total of 600 questionnaires were distributed through emails and other social media sources because of prevailing COVID-19 conditions. In response, 400 complete questionnaires were returned, constituting a response rate of $67 \%$. Further, Multiple linear regression analysis is used to measure the impact of technology adoption on the performance of the employees of commercial banks from selected South Asian economies. All possible precautionary measures are considered to make sure the authenticity of data. SPSS is used for statistical analyses of the study.

\subsection{Measures}

Validated scales were used to measure the constructs. The aggregate value of Cronbach alpha is 0.855 for all measures. The responses to the items were measured using a five-point likert scale ranging from $1=$ strongly disagree, $2=$ disagree, $3=$ neutral, $4=$ agree, $5=$ strongly agree. We received scattered answers by respondents of commercial banks of selected countries.

\subsection{Technological Change}

The Items of the scale for technological transformation includes items like "Organization has experienced significant technological change in the past" and "Organization has significantly changed the processes and equipment to cater the changing production needs".

\subsection{Employee Performance}

The Items of the scale for Employee Performance include items like, "My individual goals directly support the goals of the organization", "My performance is better than that of other workers with similar qualifications in other organizations" and "I am satisfied with my performance because it is mostly good". 


\subsubsection{Supervisor Support}

The Items of the scale for Supervisor Support include items like, "My supervisor gives enough time for me to practice the skills that I have learned during training", "Supervisor praises me when I do my job well", "My supervisor able to solve any workrelated problems", "Interested to learn new knowledge and skills in training".

\subsubsection{Incentives}

The Items of the scale for Incentives include items like, "I am satisfied with the incentives provided by the organization", "Technological change played a key role in changing compensation structures of the organization", and "I am satisfied with my salary and other benefits".

\subsubsection{Training}

The Items of the scale for Incentives include items like "After Technological change, number of training(s) provided was sufficient for maintaining my performance" "After Technological change, content of training provided was sufficient for maintaining my performance" and "My performance on new processes/equipment increased with the help of training".

\section{Empirical Findings}

In this section, the study presents descriptive statistics and regression analysis about to explore the nexus of technology-performance for the employees of commercial banks from selected South Asian economies. Likewise, the influence of supervisor support, training, and incentives on the relationship between technological change and employee performance of commercial banks is also considered in handful way.

\subsection{Descriptive Statistics}

The values of the descriptive means, ranges and, standard deviations of the variables are presented in Table 1. The values of mean show that most of the responses are inclined towards positive direction. The values for standard deviations are low which depict that variation in the data is low.

\section{Table 1}

\section{Descriptive Statistics}

\begin{tabular}{llllll}
\hline Variables & N & Minimum & Maximum & Mean & Std. Deviation \\
\hline Technology & 400 & 3.90 & 5.10 & 4.4840 & .34416 \\
Supervisor & 400 & 4.10 & 4.90 & 4.2040 & .26412 \\
Training & 400 & 2.30 & 5.10 & 2.7480 & .55470 \\
Incentives & 400 & 4.10 & 4.50 & 3.2420 & .23616 \\
Performance & 400 & 3.40 & 12.40 & 4.4780 & .82552 \\
\hline
\end{tabular}

\subsection{Regression Analysis}

Multiple linear regression analysis is used to measure the impact of technology adoption during COVID-19 on employees' performance in Table 2. The values of $\mathrm{R}^{2}$ are properly depicting that variance of independent variables are properly explained to total variance as the Goodness-of-Fit for model. The adjusted $\mathrm{R}^{2}$ is indicating properly the 
percentage of variation explained by the technological transformation that actually affects the employees' performance in commercial banks of selected south Asian countries.

Table 2

Technological Transformation \& Employees' Performance

\begin{tabular}{llll}
\hline Dependent Variable: & $\begin{array}{c}\text { Employees' } \\
\mathbf{R}^{\mathbf{2}}\end{array}$ & $\begin{array}{c}\text { Performance in Commercial Banks } \\
\text { Adjusted } \mathbf{R}^{\mathbf{2}}\end{array}$ & $\mathbf{F}$ \\
\hline Technology & 0.130 & 0.038 & 1.302 \\
Supervisor & 0.321 & -0.139 & 0.598 \\
Training & 0.172 & -0.218 & 0.477 \\
Incentives & 0.398 & 0.106 & 1.298 \\
\hline
\end{tabular}

The F-test is also reflecting that overall significance of variables fits in with other regression statistics. The values of $\mathrm{R}^{2}$, adjusted $\mathrm{R}^{2}$, and $\mathrm{F}$ show that the model is significant and the employees' performance as dependent variable is significantly explained by the independent variables. There are several key goodness-of-fit statistics for regression analysis.

Table 3

Pearson Correlation Analysis

\begin{tabular}{ll}
\hline Variables & Job Satisfaction \\
\hline Technological Transformation & 1.000 \\
Training & 0.793 \\
Supervisor Support & 0.588 \\
Incentives & 0.615 \\
\hline
\end{tabular}

For the data analysis, we have also used Pearson correlation in Table 3. It shows that there exists a positive relationship between, employee performance and technological transformation, and training, incentives and supervisor support positively moderate the relationship between technological transformation and employee performance of commercial banks in the amidst pandemic era.

On basis of econometric results, the impact of technological transformation on employee performance of commercial banks from selected South Asian economies of Bangladesh, India, Sri Lanka, Maldives, and Pakistan in the Amidst Pandemic Era. Further, the impact of technological transformation (TT) moderated by supervisor support (SS), incentives (IN) Training ( $T$ ) is also found statistically significantly related to employee performance (EP) of commercial banks. Hence we accept all above mentioned four hypotheses on basis of empirical evidence as reflected in Table $2 \&$ Table 3. Our results also support us to meet the objectives of study successfully and provide policy guideline to stimulate economic activities in the Amidst Pandemic of COVID-19 Era. The results are in line with existing literature of Trushkina, et al., (2020), (Angioha et al., 2020), Li, et al., (2020), (Molino et al., 2020) We find that the commercial banks have potential to play a vital role in increasing their employees' performance by accepting technological change and in to reduce the adverse socioeconomic effects of COVID-19 in the selected South Asian economies of Bangladesh, India, Sri Lanka, Maldives, and Pakistan.

\section{Conclusion}

The technological transformation affects the employees' performance positively if provided with supervisor support, effective training and incentives in the commercial banks of selected South Asian economies of Bangladesh, India, Sri Lanka, Maldives, and Pakistan 
during COVID-19 pandemic. This relationship is also backed by a strong theoretical support. Both social learning and identity theory affirms this relationship for commercial banks. This study focuses on commercial banks and reveals some remarkable results. These results indicate that employees of the commercial banks perceive a high level of performance in case of organizational restructuring and technological change if they are provided with supervisor support, effective training, and accurate compensation. It also highlights the fact that the employees are not given proper feedback regarding what is expected by them which is the performance goals, criteria or standards. They may be ambiguous and unclear about their tasks and responsibilities. So, supervisor support is a principal factor in enhancing employee performance and needs to be practiced in vibrant banking organizations. All of them led us towards the abovementioned measures that should be taken into consideration if we intend to improve the employee performance during these bitter days of COVID-19. Only this is the way to increase organizational effectiveness with the best professional practices of human resources management.

\subsection{Recommendations}

The findings of study clearly recommend that top management of corporations should adopt technological transformations quickly to increase in employees' performance. These steps will stimulate overall organizational effectiveness in retaining employees through supervisor support, effective training, and accurate compensation. Corporate sector is recommended to consider supervisor support, effective training, and incentives as potential measures of performance of emerging organizations. Further, government can also revise supervisory role in line with above findings to accelerate the growth corporate sector in unfavorable conditions of COVID-19.

\subsection{Limitations and Future research}

The limitations of this study include the limited time frame. We think that a deeper and more thorough research effort could have been done if the time span is not so narrow. Another limit is a limited sample size which can be extended for other financial corporations. More generalizable results could have been drawn by covering a larger portion of the population. Probability sampling technique has been used for this research, whereas future research can also employ non-probability sampling. Further research should be done in this sector regarding the impact of technological change on organizational effectiveness because there is limited research on this phenomenon particularly in emerging banking firms. The prevailing pandemic COVID-19 is a big constraint in collecting data through physical visits for accuracy of responses. Once it ends with the blessings of Allah Almighty, we can conduct research with the best way.

\section{References}

Angioha, P. U., Enukoha, C. U., Agba, R. U., \& Ikhizamah, G. U. (2020). Information technology predictor variables and employee productivity in commercial banks. JINAV: Journal of Information and Visualization, 1(1), 44-52.

Ervinta', T. T. V., Prihanto, J. N., \& Sudiyono, K. A. (2021). Enhancing Employees' Digital Experience Through Internal Platform. Paper presented at the ICEBE 2020: Proceedings of the First International Conference of Economics, Business \& Entrepreneurship, ICEBE 2020, 1st October 2020, Tangerang, Indonesia.

Martínez-Caro, E., Cegarra-Navarro, J. G., \& Alfonso-Ruiz, F. J. (2020). Digital technologies and firm performance: The role of digital organisational culture. Technological Forecasting and Social Change, 154, 119962. 
Molino, M., Cortese, C. G., \& Ghislieri, C. (2020). The promotion of technology acceptance and work engagement in industry 4.0: From personal resources to information and training. International journal of environmental research and public health, 17(7), 2438.

Prasad, K., Vaidya, R. W., \& Mangipudi, M. R. (2020). Effect of occupational stress and remote working on psychological well-being of employees: an empirical analysis during covid-19 pandemic concerning information technology industry in hyderabad. Indian Journal of Commerce and Management Studies, 11(2), 1-13.

Trushkina, N., Abazov, R., Rynkevych, N., \& Bakhautdinova, G. (2020). Digital transformation of organizational culture under conditions of the information economy. Virtual Economics, 3(1), $7-$ 38.

Vahdat, S. (2021). The role of IT-based technologies on the management of human resources in the COVID-19 era. Kybernetes.

Wolor, C. W., Solikhah, S., Fidhyallah, N. F., \& Lestari, D. P. (2020). Effectiveness of E-Training, ELeadership, and Work Life Balance on Employee Performance during COVID-19. The Journal of Asian Finance, Economics, and Business, 7(10), 443-450. 